AGRARIS: Journal of Agribusiness and Rural Development Research

Vol. 5 No. 2 Juli-Desember 2019
Ungki Prabowo Putra1*, Irham², Lestari Rahayu Waluyati

${ }^{1}$ Program Pasca Sarjana Magister Manajemen Agribisnis, Fakultas Pertanian, Universitas Gadjah Mada, Yogyakarta

${ }^{2}$ Departemen Sosial Ekonomi Pertanian, Fakultas Pertanian, Universitas Gadjah Mada, Yogyakarta

*)Email korespondensi: ungkiprabowo@gmail.com

\section{Pengaruh Orientasi Ekonomi dan Kesadaran Lingkungan terhadap Produktivitas dan Rendemen Tebu Rakyat Pabrik Gula Wonolangan}

\section{Effects of Economic Orientation and Environmental Awareness on Productivity and Yield of Smallholder Sugarcane in Wonolangan Sugar Factory}

DOI: http://dx.doi.org/10.18196/agr.5285

Keywords: Economic Orientation, Environmental Awareness, Productivity,

The increasing of sugarcane productivity and yield is not only affected by factors of production such as seeds, fertilizer, labors, and herbicides. Other factors such as economic orientation and environmental awareness also show their effects on sugarcane productivity and yield. This research was conducted to determine the effect of economic orientation and environmental awareness both on productivity and yield of sugarcane community partners in the Wonolangan Sugar Factory. The study was conducted in Probolinggo and Lumajang Regency with 102 samples of farmers selected using simple random sampling. The measurement of the level of economic orientation and environmental awareness was carried out using Likert scale and was categorized as low, medium and high. The influence of economic orientation and environmental awareness both on productivity and yield of sugar cane were analyzed using multiple regression with the Cobb Douglas production function. Based on the results, the economic orientation and environmental awareness of farmers were relatively high and could increase sugarcane productivity and yield.
Yield.

\section{INTISARI}

Peningkatan baik pada produktivitas dan rendemen tebu tidak hanya dipengaruhi oleh faktor-faktor produksi seperti bibit, pupuk, tenaga kerja dan herbisida. Faktor-faktor lain seperti orientasi ekonomi dan kesadaran lingkungan juga menunjukkan pengaruhnya terhadap produktivitas dan rendemen tebu. Penelitian ini dilakukan untuk mengetahui pengaruh orientasi ekonomi dan kesadaran lingkungan baik pada produktivitas dan rendemen tebu rakyat mitra Pabrik Gula Wonolangan. Penelitian dilaksanakan di Kabupaten Probolinggo dan Kabupaten Lumajang dengan 102 sampel petani yang dipilih menggunakan acak sederhana. Pengukuran tingkat orientasi ekonomi dan kesadaran lingkungan dilakukan dengan skala likert dan dikategorikan menjadi rendah, sedang dan tinggi. Pengaruh orientasi ekonomi dan kesadaran lingkungan baik pada produktivitas dan rendemen tebu dianalisis dengan regresi berganda menggunakan fungsi produksi Cobb Douglas. Berdasarkan hasil analisis, orientasi ekonomi dan kesadaran lingkungan petani tergolong tinggi serta dapat meningkatkan produktivitas dan rendemen tebu.

Kata kunci : Kesadaran Lingkungan, Orientasi Ekonomi, Produktivitas, Rendemen 


\section{PENDAHULUAN}

Berbagai upaya dilakukan untuk meningkatkan ekonomi petani, salah satunya dilakukan melalui peningkatan produksi komoditas yang diusahakan. Aspek ekonomi dinyatakan berhasil bila produksi pertanian tidak hanya mampu untuk mencukupi kebutuhan, tetapi juga dapat memberikan pendapatan yang cukup untuk petani (Mayrowani, 2012). Peningkatan secara ekonomi dilakukan dengan meningkatkan modal untuk persiapan lahan, penyiangan dan penanaman sehingga menghasilkan peningkatan hasil tebu (Owino, Odondo, \& Nelson, 2018). Sifat petani saat ini yang cenderung subsisten, mengindikasikan bahwa masih banyak petani yang belum memiliki orientasi ekonomi dalam menjalankan usahataninya. Petani perlu dilatih dan diberikan motivasi oleh pemerintah dan penyuluh agar orientasi ekonomi dapat tumbuh. Penyediaan pelatihan keterampilan manajemen bisnis dan cara menangani masalah-masalah dirasa perlu diberikan kepada petani untuk membantu meningkatkan hasil panen (Masuku, 2011). Hal positif yang dihasilkan yakni petani yang memiliki orientasi ekonomi melihat pertanian sebagai sarana memperoleh pendapatan dan semua keputusan didasarkan ekonomi (Reimer, Thompson, \& Prokopy, 2012).

Beberapa fakta menunjukkan kekhawatiran terjadinya kerusakan lahan dan lingkungan pertanian yang berdampak pada ketidakberlanjutan produksi pertanian dikemukakan banyak kalangan. Upaya pengurangan bahan kimia dilakukan, agar dapat menjaga kondisi lingkungan pertanian tetap baik, karena selain menambah biaya produksi, penggunaan bahan kimia berlebihan mengakibatkan kerugian bagi kelestarian lahan dan lingkungan (Las, Subagyono, \& Setiyanto, 2006) serta membahayakan kesehatan petani (Raza et al., 2019). Petani tebu sering menggunakan bahan-bahan kimia seperti pupuk dan insektisida untuk meningkatkan produksi, sedangkan dampak negatif yang ditimbulkan berupa resistensi hama dan pencemaran lingkungan bertambah seiring penggunaan bahan-bahan tersebut secara berlebihan (Singh, Singh, Anwar, \& Solomon, 2011). Oleh karena itu peningkatan produksi pertanian harus tetap memperhatikan kelestarian sumber daya alam dan lingkungan. Usahatani tebu tidak memerlukan bahan kimia berlebihan, namun sering ditemukan praktik penggunaan bahan kimia secara berlebih dengan alasan peningkatan produksi. Kurangnya lembaga untuk mengawasi penggunaan bahan kimia secara aman tanpa membahayakan kesehatan dan mencemari lingkungan saat ini menjadi permasalahan yang perlu dipertimbangkan (Butler-Dawson et al., 2018)

Penelitian yang telah dilakukan sebelumnya, produktivitas usahatani tebu dipengaruhi berbagai macam faktor input yaitu varietas, pestisida, tebang muat angkut, dan tenaga kerja manusia karena masing-masing faktor memiliki pengaruh (Reza, Riazi, $\&$ Khan, 2016). Pemupukan dengan dosis yang sesuai dan diberikan pada tanaman di waktu yang tepat dapat meningkatkan produktivitas tebu (Mastur, Syafaruddin, \& Syakir, 2015). Penambahan pemberian insektisida diharapkan dapat mengurangi resiko-resiko dalam upaya peningkatan produktivitas tebu (Upreti \& Singh, 2017). Selain itu perbaikan kondisi lahan dan proses pemanenan juga mempengaruhi tinggi rendahnya produktivitas usahatani tebu mengingat lahan harus tetap terjaga kandungan unsurhara untuk mendapatkan hasil yang baik (Cholid, 2013; Hakim, 2010)

Penelitian lain mengenai rendemen telah dilakukan beberapa peneliti di Indonesia. Beberapa penyebab rendahnya hasil rendemen tebu rakyat sangat kompleks mulai dari proses budidaya sampai pengangkutan. Pemilihan bibit yang baik yang sesuai dengan kondisi lahan akan berpengaruh terhadap rendemen yang dihasilkan, pemberian pestisida dapat mengurangi serangan hama dan penyakit pada tebu serta penggunaan tenaga kerja yang cukup serta terampil berdampak baik tehadap rendemen yang dihasilkan (Mazwan \& Masyhuri, 2019; Sutrisno, 2009). Untuk proses pemanenan tebu disarankan saat musim kering supaya kandungan air batang tebu menurun dan prinsip yang digunakan untuk panen tebu adalah MBS (Manis, Bersih dan Segar dan proses tebang angkut harus dilakukan dengan baik agar kotoran yang terangkut tidak melebihi batas maksimal (Apriawan, Irham, \& Mulyo, 2015). 
Penelitian-penelitian yang telah dilakukan belum ada yang mengaitkan produktivitas dan rendemen tebu dengan orientasi ekonomi serta kesadaran lingkungan. Orientasi ekonomi dapat dikatakan sebagai tujuan dan pandangan petani dalam melakukan usahatani khususnya dalam hal pendapatan, sedangkan kesadaran lingkungan diperlukan untuk menjaga lahan pertanian supaya memberikan produksi secara berkelanjutan dengan tetap menjaga kondisi dan kelestarian lahan. Sementara itu tanaman perkebunan lain seperti kelapa sawit sudah mengkaitkan faktor orientasi ekonomi dan kesadaran lingkungan terhadap hasil produksi dan memiliki pengaruh yang positif Keberadaan faktor orientasi ekonomi dan kesadaran lingkungan diharapkan dapat meningkatkan pendapatan petani serta tetap menjaga kelestarian lingkungan. Tujuan penelitian ini adalah (1) untuk mengetahui tingkat orientasi ekonomi dan kesadaran lingkungan petani dan (2) untuk mengetahui apakah orientasi ekonomi dan kesadaran lingkungan mempengaruhi produktivitas serta rendemen tebu rakyat Pabrik Gula Wonolangan.

\section{METODE PENELITIAN}

Penelitian dilaksanakan pada petani mitra Pabrik Gula Wonolangan dengan pertimbangan Pabrik Gula Wonolangan menjadi salah satu dari enam pabrik gula PTPN XI yang diupayakan dapat meningkatkan kapasitas produksi. Peningkatan kapasitas produksi memerlukan bahan baku tebu banyak dari petani. Metode pengambilan sampel petani tebu yang digunakan adalah metode acak sedehana dengan jumlah sampel 102 petani dari 700 petani data diambil dengan wawancara dengan panduan kuisioner. Pengukuran skala likert dan analisis regresi berganda dengan model produksi Cobb Douglas digunakan dalam penelitian ini. Pengukuran skor dengan skala likert digunakan untuk mengetahui tingkat orientasi ekonomi dan kesadaran lingkungan petani sedangkan analisis regresi berganda digunakan untuk menganalisis orientasi ekonomi dan kesadaran lingkungan dalam mempengaruhi produktivitas dan rendemen tebu rakyat di Pabrik Gula Wonolangan.

\section{PENGUKURAN ORIENTASI EKONOMI}

Tingkat orientasi ekonomi petani diukur menggunakan skala likert satu sampai lima dengan menggunakan kuisioner yang terdiri dari dua belas pernyataan dan dibagi men jadi empat indikator utama yaitu perencanaan keuntungan, penggunaan modal, perencanaan produksi dan perluasan lahan. Skor 1 jika petani sangat tidak setuju dengan pernyataan, skor 2 jika petani kurang setuju dengan pernyataan, skor 3 jika petani netral dengan pernyataan, skor 4 jika petani setuju dengan pernyataan dan skor 5 jika petani sangat setuju dengan pernyataan. Total skor dari semua pernyataan kemudian dijumlahkan dan dikategorikan menjadi tiga kategori orientasi ekonomi yaitu : kategori "rendah" dengan skor 12 sampai 27, kategori "sedang" dengan skor 28 sampai 44 dan kategori "tinggi" dengan skor 45 sampai 60.

\section{PENGUKURAN KESADARAN LINGKUNGAN}

Pengukuran tingkat kesadaran lingkungan juga diukur menggunakan skala likert satu sampai lima dengan menggunakan kuisioner yang terdiri dari empat belas pernyataan dan dibagi menjadi empat indikator utama yaitu penggunaan pupuk kimia, penggunaan pestisida dan herbisida kimia, keselamatan tenaga kerja dan kerusakan tanah. Skor 1 jika petani sangat tidak setuju dengan pernyataan, skor 2 jika petani kurang setuju dengan pernyataan, skor 3 jika petani netral dengan pernyataan, skor 4 jika petani setuju dengan pernyataan dan skor 5 jika petani sangat setuju dengan pernyataan. Total skor dari semua pernyataan kemudian dijumlahkan dan dikategorikan menjadi tiga kategori kesadaran lingkungan yaitu : kategori "rendah" dengan skor 14 sampai 33, kategori "sedang" dengan skor 34 sampai 52 dan kategori "tinggi" dengan skor 53 sampai 70.

\section{PENGARUH ORIENTASI EKONOMI DAN KESADARAN LINGKUNGAN TERHADAP PRODUKTIVITAS}

Pengaruh orientasi ekonomi dan kesadaran lingkungan terhadap produktivitas dianalisis dengan regresi berganda menggunakan model fungsi produksi Cobb Douglas sebagai berikut : 
$\mathrm{Y}=\mathrm{aX} 1^{\mathrm{b} 1} \mathrm{X} 2^{\mathrm{b} 2} \mathrm{X} 3^{\mathrm{b} 3} \mathrm{X} 4^{\mathrm{b} 4} X 5^{\mathrm{b} 5} \mathrm{D} 1^{\mathrm{b} 6} \mathrm{D} 2^{\mathrm{b} 7} \mathrm{D} 3^{\mathrm{b} 8} \mathrm{D} 4^{\mathrm{b} 9} \mathrm{e}$

Kemudian dilinierkan menjadi :

$\operatorname{Ln} Y=\operatorname{Ln} a+b_{1} \operatorname{Ln} X_{1}+b_{2} \operatorname{Ln} X_{2}+b_{3} \operatorname{Ln} X_{3}+b_{4} \operatorname{Ln} X_{4}$

$+b_{5} \operatorname{Ln} X_{5}+b_{6} D_{1}+b_{7} D_{2}+b_{8} D_{3}+b_{9} D_{4}+e$

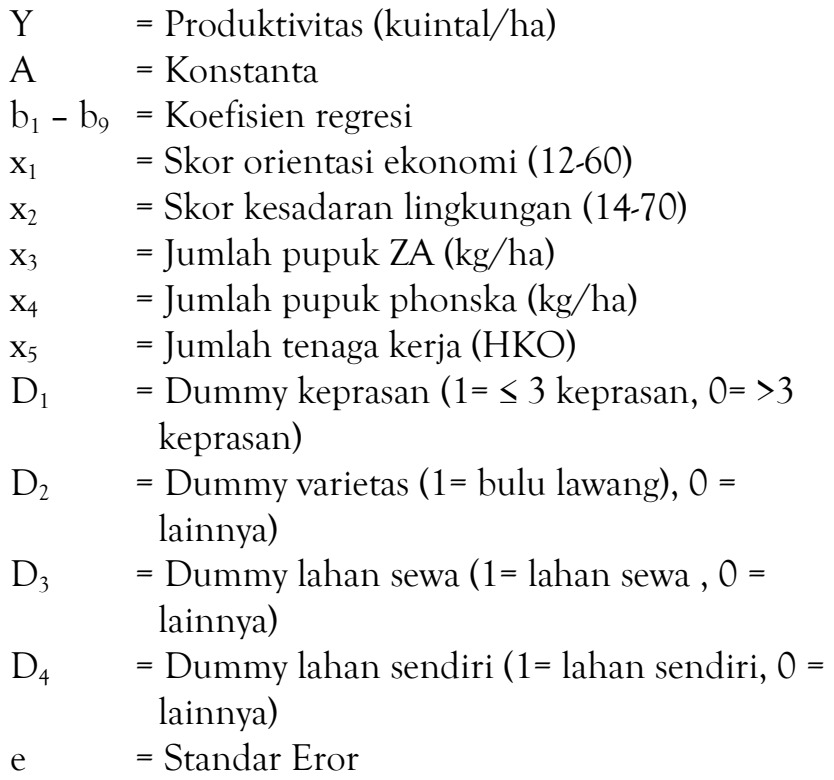

\section{PENGARUH ORIENTASI EKONOMI DAN} KESADARAN LINGKUNGAN TERHADAP RENDEMEN

Pengaruh orientasi ekonomi dan kesadaran lingkungan terhadap rendemen dianalisis dengan regresi berganda menggunakan model fungsi produksi Cobb Douglas sebagai berikut :

$\mathrm{Y}=\mathrm{aX}^{\mathrm{b} 1} \mathrm{X} 2^{\mathrm{b} 2} \times 3^{\mathrm{b} 3} \times 4^{\mathrm{b} 4} \times 5^{\mathrm{b} 5} \times 6^{\mathrm{b} 6} \mathrm{D} 1^{\mathrm{b} 7} \mathrm{D} 2^{\mathrm{b} 8} \mathrm{D} 3^{\mathrm{b} 9}$ $\mathrm{D} 4^{\mathrm{b} 10} \mathrm{e}$

Kemudian dilinierkan menjadi :

$\operatorname{Ln} Y=\operatorname{Ln} a+b_{1} \operatorname{Ln} X_{1}+b_{2} \operatorname{Ln} X_{2}+b_{3} \operatorname{Ln} X_{3}+b_{4} \operatorname{Ln} X_{4}$ $+b_{5} \operatorname{Ln} X_{5}+b_{6} \operatorname{Ln} X_{6}+b_{7} D_{1}+b_{8} D_{2}+b_{9} D_{3}+b_{10} D_{4}+e$

$\begin{aligned} \mathrm{Y} & =\text { Rendemen }(\%) \\ \mathrm{A} & =\text { Konstanta } \\ \mathrm{b}_{1}-\mathrm{b}_{10}= & \text { Koefisien regresi } \\ \mathrm{x}_{1} & =\text { Skor orientasi ekonomi }(12-60) \\ \mathrm{x}_{2} & =\text { Skor kesadaran lingkungan }(14-70) \\ \mathrm{x}_{3} & =\text { Jumlah pupuk ZA }(\mathrm{kg} / \mathrm{ha}) \\ \mathrm{x}_{4} & =\text { Jumlah pupuk phonska }(\mathrm{kg} / \mathrm{ha}) \\ \mathrm{x}_{5} & =\text { Jumlah tenaga kerja }(\mathrm{HKO}) \\ \mathrm{x}_{6} & =\text { Jarak lahan ke PG }(\mathrm{km}) \\ \mathrm{D}_{1} & =\text { Dummy keprasan }(1=\leq 3 \text { keprasan, } \mathrm{O}=>3 \\ & \text { keprasan }) \\ \mathrm{D}_{2} & =\text { Dummy varietas }(1=\text { bulu lawang }) \mathrm{O}= \\ & \text { lainnya })\end{aligned}$

$\mathrm{D}_{3}=$ Dummy lahan sewa $(1=$ lahan sewa , $0=$ lainnya)

$\mathrm{D}_{4} \quad=$ Dummy lahan sendiri $(1=$ lahan sendiri, $0=$ lainnya)

$\mathrm{e} \quad=$ Standar Eror

Sebelum dilakukan analisis regresi berganda, terlebih dahulu harus dilakukan uji asumsi klasik. Uji asumsi klasik yang digunakan diantaranya normalitas, multikolinearitas dan heteroskedasitas. Pengujian parameter yang digunakan adalah statistik uji $\mathrm{F}$ untuk uji secara serempak, adjusted $\mathrm{R}^{2}$ untuk mengetahui jumlah bagian dari variasi total yang dapat diterangkan oleh model, dan uji t untuk uji secara parsial.

\section{HASIL DAN PEMBAHASAN}

Tabel 1 menggambarkan kondisi usahatani tebu petani mitra Pabrik Gula Wonolangan. Dilihat dari nilai rata-rata produktivitas dan rendemen terakhir yang diperoleh, nilai tersebut berada lebih tinggi dari pada rata-rata produktivitas dan rendemen seluruh pabrik gula PTPN XI. Salah satu upaya petani untuk meningkatan produktivitas dan rendemen dengan menggunakan pupuk ZA dan phonska, tetapi ada sedikit petani yang tidak menggunakan pupuk phonska karena harganya yang tinggi. Sedangkan penggunaan tenaga kerja pada umumnya memerlukan jumlah yang besar pada saat tebang muat angkut. Rata-rata lokasi lahan petani mitra berada di Kabupaten Lumajang yang berbeda kabupaten dengan Pabrik Gula Wonolangan sehingga jarak lahan yang ditempuh relatif jauh.

TABEL 1. KONDISI USAHATANI TEBU PETANI

\begin{tabular}{lcrcc}
\hline \multicolumn{1}{c}{ Keterangan } & Satuan & Minimum & Maksimum & Rata-rata \\
\hline Produktivitas & Kuintal/ha & 550 & 950 & 760 \\
Rendemen & Persen & 6,5 & 9,2 & 8 \\
Pupuk Za & $\mathrm{Kg} / \mathrm{ha}$ & 100 & 700 & 350 \\
Pupuk Phonska & $\mathrm{Kg} / \mathrm{ha}$ & 0 & 350 & 160 \\
Jumlah Tenaga Kerja & $\mathrm{HOK}$ & 62 & 122 & 83 \\
Jarak Lahan Ke PG & $\mathrm{Km}$ & 19 & 45 & 30 \\
\hline
\end{tabular}

Sumber : Data Primer, 2019 (Diolah)

Usahatani tebu petani mayoritas sudah mengalami keprasan lebih dari standar yaitu lebih dari tiga keprasan, penggunaan varietas di dominasi bulu lawang dengan persentase $92 \%$ dan hanya sedikit 
petani yang tidak memili lahan sewa dengan persentase $27 \%$.

\section{TINGKAT ORIENTASI EKONOMI DAN KESADARAN LINGKUNGAN}

Tingkat orientasi ekonomi dan kesadaran lingkungan dibagi menjadi tiga kategori yaitu tinggi, sedang, dan rendah. Pada Tabel 2, mayoritas orientasi ekonomi petani berada pada kategori tinggi. Petani dikatakan termasuk dalam orientasi ekonomi kategori tinggi ketika mempunyai perencanaan keuntungan yang akan didapat dalam usahatani dan dilihat dari penggunaan modal yang digunakan serta luas lahan untuk usahatani tebu. Selanjutnya orientasi ekonomi kategori sedang menunjukkan petani yang umumnya masih kekurangan modal dan kurangnya pengetahuan bisnis mengenai usahatani tebu. Ketersediaan modal yang terdapat dalam ketiga kategori tersebut berkaitan dengan pembelian input-input produksi dan biaya tenaga kerja (Owino et al., 2018). Berdasarkan informasi dilapangan, mayoritas petani dengan orientasi ekonomi tinggi berpendapat bahwa, usahatani tebu memberikan keuntungan yang tinggi sehingga bersedia untuk mengeluarkankan modal yang besar dan berupaya memperluas usahatani tebu agar mendapatkan keuntungan yang lebih baik.

\section{TABEL 2. TINGKAT ORIENTASI EKONOMI DAN KESADARAN LINGKUNGAN} PETANI DALAM USAHATANI TEBU

\begin{tabular}{lccc}
\hline Orientasi Ekonomi & Persentase (\%) & Kesadaran Lingkungan & Persentase (\%) \\
\hline Rendah & 0,00 & Rendah & 0,98 \\
Sedang & 34,31 & Sedang & 49,02 \\
Tinggi & 65,69 & Tinggi & 50,00 \\
\hline Total & 100 & & 100
\end{tabular}

Sumber: Data Primer, 2019 (Diolah)

Hasil yang sama menunjukkan mayoritas petani juga memiliki kesadaran lingkungan yang tinggi (Tabel 2). Fakta dilapangan menunjukkan adanya pengurangan penggunaan bahan-bahan kimia pestisida dan herbisida yang dilakukan oleh petani. Pengurangan bahan-bahan kimia yang dilakukan petani bertujuan menjaga kesuburan tanah dan menjaga lingkungan. Menurut petani, lahan yang diberikan bahan kimia secara terus-menerus dapat mengakibatkan produksi usahatani tebu menurun dan mengurangi keuntungan. Penggunaan bahan kimia dalam jangka waktu lama dapat memberikan dampak buruk bagi usahatani yang dilakukan petani (Raza et al., 2019). Petani dengan kategori rendah dan sedang umumnya melakukan usahatani tebu dilahan sewa sehingga tidak terlalu mementingkan akibat yang terjadi pada lahan jika menggunakan bahan-bahan kimia secara berlebih dan dalam jangka waktu yang lama. Petani dengan kategori rendah dan sedang hanya bertujuan memaksimalkan produksi tanpa memperhatikan akibat yang terjadi pada lingkungan, oleh karena itu petani dalam kategori tersebut perlu mendapatkan penyuluhan supaya mengerti pentingnya kesadaran terhadap lingkungan dalam menjalankan kegiatan usahatani.

\section{PENGARUH ORIENTASI EKONOMI DAN KESADARAN LINGKUNGAN TERHADAP PRODUKTIVITAS}

Pengujian normalitas data dilakukan dengan One-Sample Kolmogorov-Smirnov Test didapatkan hasil signifikansi $\geq \alpha$, maka data tersebut berdistribusi normal. Nilai VIF semua variabel dibawah 10 dan nilai tolerance lebih besar dari 0,1 hal ini menunjukkan model terbebas multikolinearitas. Nilai chi-square hitung $\leq$ chi-square tabel menunjukkan data terbebas dari gangguan heteroskedasitas.

Hasil analisis regresi berganda (tabel 3) menunjukkan uji F signifikan dengan F hitung 12,156 yang berarti variabel terikat yaitu produktivitas tebu rakyat secara bersama-sama dipengaruhi oleh variabel bebasnya. Nilai adjusted $R^{2}$ sebesar 0,436, menunjukkan sebesar $43,6 \%$ faktor-faktor yang mempengaruhi produktivitas dapat dijelaskan oleh variabel bebas di dalam model, sedangkan 56,4\% dijelaskan oleh variabel lain yang tidak ada pada model. Variabel lain yang mempengaruhi produktivitas yaitu insektisida, ketersediaan air dan sinar matahari (Tando, 2017; Upreti \& Singh, 2017).

Berdasarkan nilai koefisien diketahui orientasi ekonomi berpengaruh langsung dan positif terhadap produktivitas yang berarti setiap orientasi ekonomi meningkat $1 \%$ produktivitas meningkat 0,193\%. Mayoritas petani berada dikategori orientasi ekonomi tinggi, hal ini ditunjukkan dengan proses perencanaan dalam usahatani tebu. Untuk mendapatkan produktivitas tebu yang baik, petani berusaha semaksimal untuk melakukan perencanaanperencanaan yang terkait dengan penghitungan modal 
yang digunakan, biaya yang dikeluarkan dan pendapatan yang diterima setelah tebu digiling.

TABEL 3. HASIL ESTIMASI PENGARUH ORIENTASI EKONOMI DAN KESADARAN LINGKUNGAN TERHADAP PRODUKTIVITAS

\begin{tabular}{|c|c|c|c|}
\hline Variabel & $\begin{array}{l}\text { Koefisien } \\
\text { Regresi }\end{array}$ & t-hitung & Sig \\
\hline Constanta & $4,256^{* * *}$ & 10,383 & 0,000 \\
\hline Ln_Orientasi Ekonomi & $0,193^{* *}$ & 2,025 & 0,046 \\
\hline Ln_Kesadaran Lingkungan & $0,144^{* *}$ & 2,344 & 0,021 \\
\hline Ln_Pupuk ZA & $0,046^{* *}$ & 2,571 & 0,012 \\
\hline Ln_Pupuk Phonska & $0,020^{* *}$ & 2,559 & 0,012 \\
\hline Ln Jumlah Tenaga Kerja & $0,180^{* * *}$ & 2,826 & 0,006 \\
\hline Dummy Keprasan & 0,026 ns & 1,165 & 0,247 \\
\hline Dummy Varietas & $-0,060^{* *}$ & $-2,139$ & 0,035 \\
\hline Dummy Lahan Sewa & $0,040^{* *}$ & 2,302 & 0,040 \\
\hline Dummy Lahan Sendiri & $-0,028^{* *}$ & 1,012 & 0,036 \\
\hline Adjusted R2 & 0,436 & & \\
\hline $\mathrm{F}_{\text {hitung }}$ & $12,156^{* * *}$ & & \\
\hline \multicolumn{4}{|l|}{ Sumber: Data Primer, 2019 (Diolah) } \\
\hline \multicolumn{4}{|l|}{ Keterangan : } \\
\hline *** $\quad=$ Signifikan $\alpha=1 \%$ & & & \\
\hline$=$ Signifikan $\alpha=5 \%$ & & & \\
\hline$=$ Tidak signifikan & & & \\
\hline
\end{tabular}

Petani bersedia menambah modal dan memperluas lahan mereka karena yakin usahatani tebu jika dilakukan dengan perencanaan usaha yang baik dapat memperoleh pendapatan yang tinggi. Penggunaan modal tinggi pada usahatani tebu berpotensi untuk meperoleh pendapatan yang lebih besar jika dibandingkan dengan penggunaan modal rendah (Owino et al., 2018).

Kesadaran lingkungan berpengaruh terhadap produktivitas, artinya setiap kesadaran lingkungan mengalami peningkatan $1 \%$ produktivitas meningkatkan 0,144\% Kerusakan lingkungan dapat terjadi karena penggunaan bahan kimia yang melebihi dosis sehingga memberikan efek buruk dan merusak lahan pertanian. Mayoritas petani sudah memahami pemberian bahan kimia secara besar tidak dapat memberikan produksi yang baik tetapi merusak tebu dan lingkungan. Akibat yang ditimbulkan dari penggunaan bahan kimia dalam jangka waktu lama mengakibatkan menurunnya kesuburan tanah (Rivai \& Anugrah, 2011). Efek dari menurunnya kesuburan tanah berdampak pada rendahnya produktivitas tebu yang dihasilkan. Berbagai upaya sudah mulai dilakukan seperti pengurangan bahan kimia pestisida dan herbisida, tetapi untuk penggunaan pupuk kimia masih tetap digunakan pada dosis yang dianjurkan.
Pupuk ZA berpengaruh dan bernilai positif sebesar 0,046, produktivitas dapat meningkat 0,046\% dengan penambahan pupuk ZA 1\%. Pupuk ZA diberikan pada tebu sesuai dengan dosis yang tepat, waktu yang tepat dan dengan cara yang tepat supaya tidak merusak tebu. Pemberian pupuk ZA yang didalamnya terkandung unsur $\mathrm{N}$ pada dosis tepat dapat meningkatkan produktivitas tebu (Mastur et al., 2015). Pemberian pupuk ZA sangat dianjurkan untuk menghasilkan tebu berkualitas karena mengandung unsur $\mathrm{N}$ yang dibutuhkan dalam usahatani tebu. Ratarata pemberian pupuk ZA sebesar $350 \mathrm{~kg} /$ hektar. Kekurangan unsur $\mathrm{N}$ dapat menyebabkan perkembangan batang tebu terganggu sehingga dapat menurunkan produktivitas tebu.

Pengaruh pupuk phonska pada produktivitas sebesar 0,020, kenaikan penggunaan pupuk phonska $1 \%$ dapat meningkatkan produktivitas $0,020 \%$. Penggunaan pupuk dalam usahatani tebu diantaranya pupuk phonska dan pupuk ZA dilakukan sesuai aturan dan tidak melebihi dosis pemakaian. Pemberian pupuk phonska dapat meningkatkan produksi usahatani tebu karena memiliki kandungan unsur pelengkap yang tidak ada dalam pupuk ZA (Zaky, Pambudy, \& Harianto, 2019). Pupuk phonska dikenal mengandung tiga unsur makro yang dibutuhkan oleh tebu dan rata-rata petani yang menggunakan pupuk phonska tidak pernah melakukan bongkar ratoon, sehingga dalam upaya memaksimalkan produktivitas tebu petani memberikan tambahan pupuk phonska. Perbandingan penggunaan pupuk phonska dengan pupuk ZA yaitu satu banding dua, karena harga pupuk phonska lebih mahal dari pada pupuk ZA.

Koefisien regresi tenaga kerja menunjukkan besarnya produktivitas tebu dipengaruhi oleh penggunaan tenaga kerja. Penambahan tenaga kerja sebesar $1 \%$ meningkatkan produktivitas $0,180 \%$. Produktivitas tebu identik dengan jumlah tenaga kerja yang dipekerjakan. Petani yang memiliki produktivitas diatas rata-rata umumnya menggunakan tenaga kerja lebih banyak dikarenakan setiap proses perawatan usahatani tebu membutuhkan tenaga yang banyak. Tenaga kerja tidak hanya dilihat dari jumlah tetapi dilihat dari kualitas pekerja. Pada proses tebang muat 
angkut kualitas dan kuantitas tenaga kerja sangat dibutuhkan agar produktivitas tebu dapat maksimal. Tenaga kerja pada lahan tegalan dapat mempengaruhi produksi tebu dikarenakan dalam proses panen membutuhkan tenaga kerja cukup besar, tetapi masih mengalami kesulitan untuk memenuhinya (Zainuddin $\&$ Wibowo, 2018).

Jumlah keprasan tidak mempengaruhi produktivitas tebu dengan koefisien regresi sebesar 0,026 sehingga tidak ada perbedaan produktivitas tebu petani yang sudah melakukan keprasan $\geq 3$ dan yang kurang dari 3 kali keprasan. Hal ini dikarenakan petani rutin memberikan pupuk yang dapat memacu pertumbuhan tebu sehingga dapat menghasilkan produktivitas baik.

Dummy varietas memiliki pengaruh terhadap produktivitas tebu yang berarti ada perbedaan produktivitas tebu antara petani yang menggunakan varietas lainnya dengan petani yang menggunakan varietas bulu lawang. Koefisien regresi sebesar -0,06 menunjukkan produktivitas tebu petani yang menggunakan varietas bulu lawang 0,06\% lebih rendah dari produktivitas tebu petani yang menggunakan varietas selain bulu lawang. Tingginya produktivitas tebu yang menggunakan varietas selain bulu lawang dikarenakan varietas PS 862 dan PS 864 termasuk varietas unggul. Namun dilapangan petani lebih memilih varietas bulu lawang dari pada PS 862 dan 864 dikarenakan petani tidak berani untuk mengambil risiko gagal panen apabila menggunakan varietas yang berbeda dari petani lainnya. Petani cenderung mengikuti petani lainnya dalam penggunaan varietas agar hasil yang didapat tidak jauh berbeda (Mazwan \& Masyhuri, 2019).

Penggunaan lahan sewa memiliki pengaruh pada produktivitas tebu yang berarti terdapat perbedaan produktivitas antara petani yang berusahatani dilahan lainnya dengan petani yang melakukan sewa. Koefisien regresi sebesar 0,040 menunjukkan produktivitas tebu petani pengguna lahan sewa $0,04 \%$ lebih besar dari produktivitas tebu petani lahan lainnya. Terjadinya perbedaan produktivitas dikarenakan petani yang menggunakan lahan sewa memiliki perencanaan usahatani yang baik dan memiliki modal besar untuk berusahatani tebu.
Penggunaan modal yang besar untuk persiapan lahan, penyiangan dan penanaman supaya produktivitas tebu dapat meningkat (Owino et al., 2018).

Dummy lahan sendiri berpengaruh terhadap produktivitas tebu dengan koefisien regresi sebesar 0,028 yang artinya produktivitas tebu petani yang berusahatani dilahan lainnya dengan produktivitas tebu petani yang memiliki lahan sendiri berbeda. Produktivitas tebu lahan sendiri 0,028\% lebih rendah dari produktivitas tebu lahan lainnya. Petani yang memiliki lahan sendiri umumnya mengalami kekurangan modal untuk pembelian input produksi usahatani tebu sehingga penggunaan input produksi tidak maksimal. Sedangkan petani yang melakukan sewa memiliki modal cukup dan berupaya untuk memaksimalkan produktivitas (Reimer et al., 2012).

\section{PENGARUH ORIENTASI EKONOMI DAN KESADARAN LINGKUNGAN TERHADAP RENDEMEN}

Pengujian normalitas data dilakukan dengan One-Sample Kolmogorov-Smirnov Test didapatkan hasil signifikansi $\geq \alpha$, maka data tersebut berdistribusi normal. Nilai VIF semua variabel dibawah 10 dan nilai tolerance lebih besar dari 0,1 hal ini menunjukkan model terbebas multikolinearitas. Nilai chi-square hitung $\leq$ chi-square tabel menunjukkan data terbebas dari gangguan heteroskedasitas.

TABEL 4. HASIL ESTIMASI PENGARUH ORIENTASI EKONOMI DAN KESADARAN LINGKUNGAN TERHADAP RENDEMEN

\begin{tabular}{lccc}
\hline \multicolumn{1}{c}{ Variabel } & $\begin{array}{c}\text { Koefisien } \\
\text { Regresi }\end{array}$ & t-hitung & Sig \\
\hline Constanta & $0,840^{* *}$ & 2,397 & 0,019 \\
Ln_Orientasi Ekonomi & $0,144^{* *}$ & 2,226 & 0,028 \\
Ln_Kesadaran Lingkungan & $0,086^{* *}$ & 2,114 & 0,037 \\
Ln_Pupuk ZA & $0,036^{* * *}$ & 2,977 & 0,004 \\
Ln_Pupuk Phonska & $-0,001^{\text {ns }}$ & $-0,228$ & 0,820 \\
Ln_Jumlah Tenaga Kerja & $0,109^{* * *}$ & 2,586 & 0,011 \\
Ln_Jarak Lahan Ke PG & $-0,099^{* *}$ & $-2,264$ & 0,002 \\
Dummy Keprasan & $0,007^{\text {ns }}$ & 0,488 & 0,626 \\
Dummy Varietas & $-0,003^{\text {ns }}$ & $-0,160$ & 0,873 \\
Dummy Lahan Sewa & $0,032^{* *}$ & 2,465 & 0,031 \\
Dummy Lahan Sendiri & $0,019^{\text {ns }}$ & 0,172 & 0,542 \\
\hline Adjusted R & 0,452 & & \\
\hline F hitung & $11,394^{* * *}$ & & \\
\hline Sumbr: Andisis Data Prin & &
\end{tabular}

Sumber: Analisis Data Primer, 2019

Keterangan :

*** $\quad=$ Signifikan $\alpha=1 \%$

** $\quad=$ Signifikan $\alpha=5 \%$

ns $\quad=$ Tidak signifikan 
Hasil analisis regresi berganda (tabel 4) menunjukkan uji $\mathrm{F}$ signifikan dengan $\mathrm{F}$ hitung 11,394, berarti variabel terikat yaitu rendemen tebu secara bersama-sama dipengaruhi oleh variabel bebasnya. Nilai Adjusted $\mathrm{R}^{2}$ sebesar 0,452, menunjukkan sebesar $45,2 \%$ faktor-faktor yang mempengaruhi rendemen dijelaskan oleh variabel bebas di dalam model, sedangkan 54,8\% dijelaskan variabel lain yang tidak ada pada model. Variabel lain yang mempengaruhi rendemen diantaranya waktu tebang, curah hujan, sinar matahari, kotoran yang terangkut, penyiangan, serangan hama penyakit dan waktu tanam (Mairiyansyah, 2018; Putra, 2012).

Orientasi ekonomi berpengaruh terhadap rendemen tebu. Orientasi ekonomi ditingkatkan menjadi lebih baik dapat mewujudkan tingginya rendemen. Artinya setiap orientasi ekonomi ditingkatkan $1 \%$ rendemen meningkatkan $0,144 \%$. Petani yang dimaksud sudah memiliki orientasi ekonomi dalam hal ini telah memperhitungkan biayabiaya dan aspek ekonomi dalam usahatani tebu. Usahatani tebu saat ini sudah memasuki dunia bisnis sehingga peran ekonomi sangat besar untuk pengambilan keputusan (Reimer et al., 2012). Petani bersedia menambah modal dan memperluas lahan garapan usahatani tebu karena yakin usahatani tebu dapat memberikan keuntungan tinggi selain itu upaya untuk memproduksi tebu semaksimal mungkin dapat dilakukan dengan cara memaksimalkan proses-proses perawatan supaya produksi tebu yang baik dapat tercapai karena dapat mempengaruhi pendapatan petani.

Upaya yang dapat dilakukan untuk meningkatkan rendemen salah satunya dengan meningkatkan kesadaran lingkungan. Kesadaran lingkungan berpengaruh positif terhadap rendemen tebu. Artinya kesadaran terhadap lingkungan meningkat $1 \%$ rendemen meningkatkan $0,086 \%$. Kesadaran lingkungan yang dimiliki petani tergolong tinggi dikarenakan petani sudah mengetahui bahaya penggunaan bahan kimia yang berlebih terhadap usahatani tebu dapat mengakibatkan rendemen tebu yang dihasilkan tidak maksimal. Selain itu penggunaan bahan kimia dapat menambah biaya oprasional, membahayakan kesehatan petani dan membunuh musuh alami (Raza et al., 2019).

Penambahan pupuk ZA $1 \%$ dapat meningkatkan rendemen dengan tambahan 0,036\% karena pupuk ZA memiliki pengaruh positif terhadap rendemen tebu petani. Pemberian pupuk ZA dapat mempengaruhi produksi tebu mengingat usahatani tebu memerlukan unsurhara makro yang terkandung pada pupuk ZA (Rohmah, Suryantini, \& Hartono, 2016). Petani menggunakan pupuk ZA dengan ratarata $350 \mathrm{~kg} /$ hektar. Penggunaan pupuk ZA dilakukan oleh petani setiap tahun karena berdasarkan pengalaman dan kondisi lahan yang ada pemberian pupuk ZA dapat meningkatkan rendemen tebu mengingat usahatani tebu memerlukan unsurhara yang tinggi diantaranya unsur nitrogen $(\mathrm{N})$ yang dapat diperoleh dari pupuk ZA.

Pupuk phonska memiliki koefisien regresi sebesar $-0,001$ dan nilai signifikan $\geq 5 \%$. Hasil ini menunjukkan bahwa pupuk phonska tidak mempengaruhi rendemen tebu petani, dikarenakan untuk memenuhi kebutuhan unsurhara tebu dalam upaya meningkatkan rendemen, petani telah memaksimalkan pemberian pupuk ZA mengingat harga pupuk phonska tinggi. Hal ini tidak sejalan dengan hasil penelitian bahwa pemberian pupuk phonska dapat mempengaruhi produksi dalam hal ini rendemen tebu karena dengan penambahan phonska unsurhara pada usahatani tebu akan semakin baik (Zaky et al., 2019).

Tenaga kerja memiliki pengaruh positif terhadap rendemen tebu. Penambahan tenaga kerja $1 \%$ dapat meningkatkan rendemen tebu dengan tambahan sebesar 0,109\%. Tenaga kerja pada usahatani tebu berpengaruh terhadap produksi tebu dalam hal ini rendemen, penggunaan tenaga kerja dengan rata-rata terbesar pada proses panen mengingat proses panen harus segera diselesaikan agar rendemen tidak turun (Mazwan \& Masyhuri, 2019). Tenaga kerja dibutuhkan dalam jumlah besar dikarenakan usahatani tebu memerlukan berbagai perawatan, biasanya penggunaan tenaga kerja dengan sistem borongan karena dianggap tidak terlalu merepotkan petani untuk mencari tenaga-tenaga untuk dipekerjakan. Jumlah tenaga kerja yang 
diperlukan dipengaruhi oleh frekuensi dalam perawatan usahatani tebu, sehingga frekuensi perawatan yang dilakukan semakin banyak tenaga kerja yang dibutuhkan akan bertambah. Selain itu proses klentek dan tebang angkut berkontribusi besar pada penggunaan tenaga kerja karena proses tersebut membutuhkan waktu pengerjaan lama dan membutuhkan beberapa hari pengerjaan.

Jarak lahan ke pabrik gula ikut menentukan rendemen dalam usahatani tebu deengan koefisien regresi sebesar -0,099. Hal ini mengindikasikan jika terjadi peningkatan $1 \%$ pada jarak lahan ke pabrik gula dapat menurunkan rendemen tebu sebesar 0,099\%. Rendemen dapat turun bila jarak waktu antara tebu ditebang sampai tebu digiling lebih dari 24 jam (Manalu, 2006). Rata-rata jarak lahan petani ke Pabrik Gula Wonolangan 30 kilometer dan pada musim giling umumnya tidak ada tebu petani yang tidak digiling pada hari yang sama. Hal yang membedakan terdapat pada lokasi lahan, semakin jauh lahan dari pabrik mengakibatkan waktu yang lebih untuk sampai digiling dan cenderung menurunkan rendemen, penurunan rendemen tidak terlalu jauh karena tebu tetap digiling pada hari yang sama.

Jumlah keprasan tidak mempengaruhi rendemen tebu dengan koefisien regresi -0,007. Artinya tidak ada perbedaan rendemen antara petani yang sudah melakukan keprasan $\geq 3$ dan yang kurang dari 3 keprasan. Petani beranggapan jika usahatani tebu masih tetap menghasilkan meskipun sudah mengalami keprasan lebih dari 3. Pengetahuan petani dalam manajemen ratoon tebu masih tergolong kurang baik yang mengakibatkan banyak petani tidak memperhatikan keprasan yang sudah dilakukan. Kurangnya pengetahuan petani diakibatkan karena hasil yang didapatkan dari usahatani tebu keprasan lebih dari 3 tidak jauh berbeda dengan yang belum mengalami keprasan lebih dari 3 (Patel \& Vejapara, 2016).

Rendemen tidak dipengaruhi oleh varietas yang digunakan sehingga tidak ada perbedaan rendemen antara petani yang menggunakan varietas bulu lawang dan yang menggunakan varietas lainnya. Tidak adanya perbedaan rendemen terjadi karena dalam proses usahatani tebu, perlakuan yang diberikan pada setiap varietas umumnya sama dengan varietas lainnya. Hal ini tidak sesuai dengan penelitian yang menyatakan bahwa rendemen usahatani tebu dapat dipengaruhi oleh varietas yang digunakan karena varietas yang digunakan dilahan yang sesuai dapat tumbuh dengan baik dan menghasilkan rendemen tinggi (Gulati et al., 2015).

Dummy lahan sewa mampu meningkatkan rendemen tebu dengan peningkatan sebesar 0,032 yang berarti terdapat perbedaan rendemen antara petani yang menggunakan lahan lainnya dengan petani yang menggunakan lahan sewa. Rendemen tebu petani lahan sewa $0,032 \%$ lebih tinggi dari rendemen petani lahan lainnya. Petani yang menggunakan lahan sewa mayoritas memiliki modal yang besar untuk usahatani tebu dan upaya peningkatan rendemen memerlukan modal yang besar, dengan modal yang besar hasil dari usahatani tebu dapat maksimal (Owino et al., 2018).

Nilai koefisien dummy lahan sendiri sebesar 0,019 tidak mempengaruhi rendemen tebu yang berarti tidak ada perbedaan rendemen antara petani yang berusahatani dilahan sendiri dengan petani petani dilahan lainnya. Hal ini terjadi karena lahan yang digunakan petani penyewa rata-rata masih dalam kondisi baik dan tidak tercemar bahan kimia sehingga rendemen yang dihasilakan sama dengan rendemen di lahan milik sendiri. Penggunaan bahan kimia dapat mengakibatkan kerusakan lahan dan menghambat pertumbuhan tebu (Las et al., 2006).

\section{KESIMPULAN}

Sebanyak $65,59 \%$ petani memiliki orientasi ekonomi tinggi dan $50 \%$ petani memiliki kesadaran terhadap lingkungan tinggi. Orientasi ekonomi, kesadaran lingkungan, pupuk $\mathrm{Za}$, pupuk phonska, tenaga kerja, varietas, lahan sewa dapat meningkatkan produktivitas dan untuk lahan sendiri menurunkan produktivitas. Sedangkan orientasi ekonomi, kesadaran lingkungan, pupuk $\mathrm{Za}$, tenaga kerja dan lahan sewa dapat meningkatkan rendemen tetapi untuk jarak lahan ke Pabrik Gula menurunkan rendemen. Upaya untuk meningkatkan produktivitas dan rendemen dapat dilakukan dengan cara 
pemberian informasi dan pemahaman terkait pentingnya indikator-indikator pada orientasi ekonomi serta kesadaran lingkungan mengingat orientasi ekonomi dan kesadaran lingkungan berpengaruh positif terhadap produktivitas dan rendemen tebu.

\section{DAFTAR PUSTAKA}

Apriawan, D. C., Irham, I., \& Mulyo, J. H. (2015). Analisis Produksi Tebu Dan Gula Di Pt. Perkebunan Nusantara Vii (Persero). Agro Ekonomi, 26(2), 159-167. https://doi.org/10 .22146/agroekonomi.17268

Butler-Dawson, J., Krisher, L., Asensio, C., Cruz, A., Tenney, L., Weitzenkamp, D., ... Newman, L. S. (2018). Risk Factors for Declines in Kidney Function in Sugarcane Workers in Guatemala. Journal of Occupational and Environmental Medicine, 60(6), 548-558. https://doi.org/10.1097/JOM.000000000000 1284

Cholid, M. (2013). Peningkatan Produktivitas dan Rendemen Tebu Melalui Pendekatan Hubungan Source-Sink. Info Teknologi Perkebunan, 5(12), 8-10.

Gulati, J. M. L., Sunmarg, C., Kar, Behra, J., Jena, S. N., \& Lenka, S. (2015). Effect of planting methods on growth pattern and productivity of sugarcane varieties. Indian Journal of Agricultural Research, 49(3), 222-228. https ://doi.org/10.5958/0976-058X.2015.00034.7

Hakim, M. (2010). Potensi Sumber Daya Lahan untuk Tanaman Tebu di Indonesia. Agrikultura, 21(1), 5-12. https://doi.org/10.24198/agrik ultura.v21i1.967

Las, I., Subagyono, K., \& Setiyanto, A. P. (2006). ISU DAN PENGELOLAAN LINGKUNGAN DALAM REVITALISASI PERTANIAN. Jurnal Penelitian Dan Pengembangan Pertanian, 25(3), 173193.

Mairiyansyah. (2018). Peluang Peningkatan Produksi Gula dan Pendapatan Petani Melalui Program Konsolidasi Pengelolaan Tebu Rakyat (Irham, A. Nurhayati, M. Cholidi, \& Daniyanto, Eds.). Yogyakarta: Phoenix.

Manalu, L. (2006). Studi Kasus Penentuan Rendemen Tebu di Pabrik Gula BUMN. Jurnal Keteknikan Pertanian, 20(1), 1-8.

Mastur, ., Syafaruddin, ., \& Syakir, M. (2015). Peran dan Pengelolaan Hara Nitrogen pada Tanaman Tebu Untuk Peningkatan Produktivitas Tebu. Perspektif, 14(2), 73-86. https://doi.org/10.21082/p.v14n2.2015.7386

Masuku, M. (2011). Determinants of sugarcane profitability: the case of smallholder cane growers in Swaziland. Asian Journal of Agricultural Sciences, 3(3), 210-214.

Mayrowani, H. (2012). Pengembangan Pertanian Organik di Indonesia. Forum Penelitian Agro Ekonomi, 30(2), 91-108. https://doi.org/10. 21082/fae.v30n2.2012.91-108

Mazwan, M. Z., \& Masyhuri, M. (2019). Alokasi Penggunaan Input Produksi Tebu Perkebunan Rakyat di Jawa Timur (Studi Kasus Petani Tebu Plasma PTPN XI). Jurnal Ekonomi Pertanian Dan Agribisnis, 3(1), 138-151. https://doi.org/10.21776/ub.jepa.2019.003.0 1.14

Owino, O. E., Odondo, A., \& Nelson, O. (2018). SocioEconomic Determinants of Sugarcane Production Among Small Scale Farmers in Nyando Sugarbelt of Kenya. EPRA International Journal of Economic and Business Review, 6(9), 37-46.

Patel, S. ., \& Vejapara, V. . (2016). Knowledge and adoption of recommended ratoon management practices by the sugarcane growers. Gujarat Journal Of Extension Education, 17(1), 77-78. https://doi.org/10. 15740/has/au/11.4/446-448

Putra, I. (2012). Faktor Yang Berpengaruh Terhadap Rendemen Tebu Studi Kasus Di Pabrik Gula Toelangan Sidoarjo Jawa Timur. Universitas Pembangunan Nasional.

Raza, H. A., Amir, R. M., Idrees, M. A., Yasin, M., Yar, G., Farah, N., ... Younus, M. N. (2019). Residual Impact Of Pesticides On Environment And Health Of Sugarcane Farmers In Punjab With Special Reference To Integrated Pest Management. Journal Global Innovation Agriculture Social Science, 7(2), 79-84.

Reimer, A. P., Thompson, A. W., \& Prokopy, L. S. (2012). The multi-dimensional nature of environmental attitudes among farmers in Indiana: Implications for conservation adoption. Agriculture and Human Values, 29(1), 29-40. https://doi.org/10.1007/s1046 0-011-9308-z

Reza, M. S., Riazi, M. H., \& Khan, M. M. H. (2016). Productivity and Profitability of Sugarcane Production in Northern Bangladesh. Indian Journal of Commerce \& Management Studies, 7(1), 0-9. 
Rivai, R. S., \& Anugrah, I. S. (2011). Konsep dan Implementasi Pembangunan Pertanian Berkelanjutan di Indonesia. Forum Penelitian Agro Ekonomi, 29(1), 13-25. https://doi.org/ 10.21082/fae.v29n1.2011.13-25

Rohmah, W., Suryantini, A., \& Hartono, S. (2016). Analisis Pendapatan Dan Tingkat Kesejahteraan Rumah Tangga Petani Tebu Tanam Dan Keprasan Di Kabupaten Bantul. Agro Ekonomi, 24(1). https://doi.org/10.22 146/agroekonomi.17382

Singh, J., Singh, R. D., Anwar, S. I., \& Solomon, S. (2011). Alternative Sweeteners Production from Sugarcane in India: Lump Sugar (Jaggery). Sugar Tech, 13(4), 366-371. https: //doi.org/10.1007/s12355-011-0110-4

Sutrisno, B. (2009). Analisis Faktor-Faktor Yang Mempengaruhi Tingkat Pendapatan Petani Tebu Pabrik Gula Mojo Sragen. Jurnal Ekonomi Manajemen Sumber Daya, 10(2), 155-164. Retrieved from https://doaj.org/ar ticle/bbc89f78a02a403188cb93d4dfca1e17

Tando, E. (2017). Peningkatan Produktivitas Tebu (Saccarum Officinarum I.) pada Lahan Kering Melalui Pemanfaatan Bahan Organik dan Bahan Pelembab Tanah Sintesis. Jurnal Biotropika, 5(3), 90-96. https://doi.org/10.21 776/ub.biotropika.2017.005.03.6

Upreti, P., \& Singh, A. (2017). An Economic Analysis of Sugarcane Cultivation and its Productivity in Major Sugar Producing States of Uttar Pradesh and Maharashtra. Economic Affairs, 62(4), 711-718. https://doi.org/10.5958/097 6-4666.2017.00087.0

Zainuddin, A., \& Wibowo, R. (2018). Analisis Potensi Produksi Tebu dengan Pendekatan Fungsi Produksi Frontir di PT Perkebunan Nusantara X. Jurnal Pangan, 27(1), 33-42.

Zaky, Y., Pambudy, R., \& Harianto, H. (2019). Analisis Efisiensi Usahatani Tebu Petani Mitra Dan Non Mitra Di Kabupaten Blora Jawa Tengah. Forum Agribisnis, 9(1), 85-106. https://doi. org/10.1017/CBO9781107415324.004 